\title{
Investigation on eggshell apex abnormality (EAA) syndrome in France: isolation of Mycoplasma synoviae is frequently associated with Mycoplasma pullorum
}

\author{
M. Cisneros-Tamayo ${ }^{1,2}$, I. Kempf ${ }^{1}$, J. Coton ${ }^{3}$, V. Michel ${ }^{4}$, S. Bougeard ${ }^{5}$, C. de Boisséson ${ }^{6}$, P. Lucas ${ }^{6}$,
} M.-H. Bäyon-Auboyer ${ }^{7}$, G. Chiron ${ }^{8}$, C. Mindus ${ }^{8}$ and A. V. Gautier-Bouchardon ${ }^{1 *}$ (D)

\begin{abstract}
Background: Mycoplasma synoviae (MS) is known to cause Eggshell Apex Abnormality (EAA) syndrome characterized by an altered shell surface with increased translucency on the apex. However, no large-scale studies have been conducted to obtain prevalence data of EAA and MS isolates associated to this syndrome. This manuscript reports the results of two field studies performed in the French poultry industry (2015-2017): focusing mainly on investigation of presence and prevalence of EAA in different types of laying hen flocks (phase 1), and isolation of MS strains from EAA-infected flocks (phase 2).

Results: The first survey included 77 farms of commercial layers in three French egg-production regions, hosting 40 flocks in alternative systems (ALT) and 56 in furnished cages (FC). Seven flocks (4 FC and 3 ALT) presented EAA clinical signs, giving a prevalence of $7.3 \%$ in this studied sample. A second independent field study was conducted to identify MS by in vitro cultivation and PCR in samples from 28 flocks with clinical signs of EAA. Different types of biological specimens were collected in EAA-affected flocks and submitted to the laboratory. M. synoviae was detected in 25/28 flocks, from both production systems (5/5 ALT and 20/23 FC). Detection of MS was significantly higher in tracheal swabs (59\%) than in cloacal (10.5\%), albumen (3.6\%) and egg yolk (1.1\%) swabs. It is worth to mention that attempts to clone MS from positive samples were often hampered by the presence of another Mycoplasma species, which showed fast growing behaviour in the selective media used in this study (Frey Medium 4 and Frey Medium 4 supplemented with erythromycin). The use of MALDI-TOF mass spectrometry in combination with next-generation sequencing (NGS) results allowed the identification of this fast growing mycoplasma as Mycoplasma pullorum, which was detected in 14 of the 25 (56\%) MS-positive flocks.

(Continued on next page)
\end{abstract}

\footnotetext{
* Correspondence: anne.bouchardon@anses.fr

${ }^{1}$ Mycoplasmology, Bacteriology and Antimicrobial Resistance Unit,

Ploufragan-Plouzané-Niort Laboratory, French Agency for Food,

Environmental and Occupational Health and Safety (ANSES), Ploufragan,

France

Full list of author information is available at the end of the article
}

(c) The Author(s). 2020 Open Access This article is licensed under a Creative Commons Attribution 4.0 International License, which permits use, sharing, adaptation, distribution and reproduction in any medium or format, as long as you give appropriate credit to the original author(s) and the source, provide a link to the Creative Commons licence, and indicate if changes were made. The images or other third party material in this article are included in the article's Creative Commons licence, unless indicated otherwise in a credit line to the material. If material is not included in the article's Creative Commons licence and your intended use is not permitted by statutory regulation or exceeds the permitted use, you will need to obtain permission directly from the copyright holder. To view a copy of this licence, visit http://creativecommons.org/licenses/by/4.0/ The Creative Commons Public Domain Dedication waiver (http://creativecommons.org/publicdomain/zero/1.0/) applies to the data made available in this article, unless otherwise stated in a credit line to the data. 
(Continued from previous page)

Conclusions: These results confirmed the presence of the EAA syndrome in MS-positive flocks of layers in France, reared in different regions and in different production systems (ALT and FC). Studies need to be conducted to test whether M. pullorum may influence the expression of clinical signs of EAA in MS-infected layer farms.

Keywords: Mycoplasma synoviae, Eggshell apex abnormalities, Layers, MALDI-TOF, Mycoplasma pullorum

\section{Background}

Infectious synovitis was first described and associated with mycoplasma infection in the USA during the early 1950's [1] and the causative organism was designated later as Mycoplasma synoviae [2]. It is a cosmopolitan microorganism in poultry production. The clinical signs of MS infection can be different according to its tropism and poultry categories. M. synoviae infection most frequently occurs as a subclinical upper respiratory infection, but more severe clinical signs and lesions may be observed when MS is associated with Escherichia coli [3], Newcastle disease or infectious bronchitis [4-6], or viruses that may cause immune suppression such as bursal disease virus [7] in chicken. M. synoviae can also induce infectious synovitis in chickens and turkeys $[1,8]$. In addition to the acute respiratory and/or articular lesions, MS infections often result in reduced growth, production, and hatchability $[9,10]$. Feberwee and collaborators [5] described the association between the presence of MS in the oviduct and the production of eggs with eggshell apex abnormalities (EAA) in layers, characterized by an altered shell surface, shell thinning, increased translucency (detectable macroscopically, particularly at candling), and the occurrence of cracks and breaks. Eggshell lesions are confined to a region of approximately $2 \mathrm{~cm}$ from the apex (top cone of the egg). This egg alteration is exacerbated by the association of MS and infectious bronchitis virus $[5,11]$. The EAA syndrome has been described in several countries $[5,10,12$, 13] and was first reported in France in 2009 [14]. The diagnosis of EAA syndrome due to MS infection in layers is initially based on epidemiological information at the farm level. Direct diagnostic confirmation can be achieved by bacteriological isolation and/or molecular assays such as MS-specific polymerase chain reaction (PCR) tests $[8,15]$. Then, several serological tests can be applied for indirect diagnosis of MS infection and according to the World Organisation for Animal Health (OIE), the rapid serum agglutination (RSA) and enzymelinked immunosorbent assay (ELISA) tests are the most commonly serological tests used for diagnosis [16].

The wide range of MS clinical signs and the multiple exacerbating factors such as other respiratory agents and stress challenges, induce a high economic impact in the poultry industry $[15,17]$. Endemic infection in commercial layer farms persists because of vertical and horizontal transmission of MS. Once contaminated, birds may carry MS for the rest of their life [18]. Mycoplasmas lack cell wall, and indirect transmission is rather unexpected for wall-less bacteria, which are supposed to be sensitive to osmotic shock, heating or chemical treatment. Biofilm formation has been evidenced in several Mycoplasma species [19, 20] including M. gallisepticum [21], but not reported so far in MS. Biofilms may be involved in persistence of mycoplasmas (by increasing resistance to antimicrobials, immune responses, heat and desiccation) and in establishment of chronic infections. $M$. synoviae may persist on feathers for up to two or 3 days at room temperature and ten to 21 days under dry conditions at $20^{\circ} \mathrm{C}$ [22]. The presence of MS in poultry farms is frequent despite the control measures and biosafety regulations implemented in different countries, mainly in grandparents stocks and breeders. An official control for MS has been implemented in The Netherlands where the stamping out is mandatory for MS positive breeder flocks [23]. In other countries, biosecurity measures, monitoring and diagnosis, antibiotic therapy, vaccination with commercial or autogenous vaccines are considered as control tools [15, 23-25]. Several studies reported temporary effect of antimicrobial treatments in EAA-affected layer flocks, with a decreased number of broken or downgraded eggs during treatment, but with a disappearance of this effect one to 2 weeks after the end of treatment [5, 12, 26, 27].

There is limited literature on the global prevalence of MS in layers. Some studies reported that MS is found in $73 \%$ of layer flocks in the Netherlands [28], 90\% in China [29], 40.3\% in Portugal [10], 72.7\% in Brazil [11], 69\% in Australia [16] and 68\% in France [18]. However, to our knowledge, no prevalence data for the EAA syndrome (production of eggs with eggshell apex abnormalities in laying-hen flocks) is available.

France is the leading table egg producer in Europe with 46 millions of commercial layers housed in 2100 farms and the main production is brown eggs (60\%) [30]. Laying farms are mainly located in Bretagne (42\%) and Pays de la Loire (11\%) (Northwest of France), NordPas-de-Calais and Picardie (11\%) (North of France) and Rhône-Alpes (9\%) (Southeast of France). French eggs are produced in furnished cages (69\%) and alternative systems (barn, free range and organic production system, $31 \%$ ) [30]. The aim of this study was to evaluate the 
status of the EAA syndrome among brown-egg layer farms in France, in the main egg-producing regions (Bretagne, Pays de la Loire and Rhône-Alpes), in flocks housed in furnished cages or alternative systems. In the first phase, the prevalence of this syndrome was calculated during a 12-month field survey (2015-2016). In the second phase, an independent 30-month laboratory study was performed, collecting samples from farms with EAA clinical signs for MS isolation and identification (2015-2017).

\section{Results}

Field survey results (phase 1): identification of farms with the EAA syndrome

Among the 126 farms selected and contacted for the study, 49 did not want to fill the questionnaire about the EAA syndrome and were not included further in the study. The reduction in the number of farms participating in the survey did not significantly affect the proportions of farms in the different production systems and regions. Thus from May 2015 to May 2016, the 77 remaining layer farms were visited, and filled the questionnaire about the EAA syndrome, for a total of 96 flocks. According to the survey results, 16 out of 77 farmers questioned (farm prevalence: $20.7 \%$, Confidence Interval $(\mathrm{CI})=12.6-31.8)$ had observed the EAA syndrome in at least one flock under production during the last 5 years (former flocks) (Table 1); on the contrary seven flocks presented EAA clinical signs at the time of visit (current flocks), giving an EAA-positive flock prevalence of $7.3 \%(\mathrm{CI}=3.2-14.9)$ in this studied sample. Altogether, EAA was reported in 22 of the 77 farms (farm prevalence: $28.6 \%, \mathrm{CI}=9.1-40.1$ ) in former or current flocks, and one farm, located in AuvergneRhône-Alpes, experienced recurrent cases (Table 1).

\section{Presence of EAA syndrome among different production systems and regions}

In total, 40 flocks in alternative systems (ALT) and 56 flocks in furnished cages (FC) were included in the survey. These farms were located in three regions: Bretagne (24 ALT and 45 FC), Pays de la Loire (6 ALT and 3 FC) and Auvergne-Rhône-Alpes (10 ALT and 8 FC). In Bretagne, four flocks in FC out of the 69 visited flocks were EAA-positive (flock prevalence: $5.8 \%, \mathrm{CI}=1.8-14.9$ ). No EAA-positive flock in ALT or FC production systems was reported in Pays de la Loire. Auvergne-Rhône-Alpes presented the highest prevalence, with three EAApositive flocks in ALT production systems out of the 18 visited flocks (flock prevalence: $16.6 \%, \mathrm{CI}=4.4-42.2$ ) (Table 1).

Results of EAA prevalence in former flocks (last 5 years) were different between both production systems. In Bretagne 11/52 poultry farmers (farm prevalence: $21.1 \%, C I=11.5-35.0)$ confirmed the occurence of the EAA syndrome in former flocks: eight farms in FC and three farms in ALT systems. In Auvergne-Rhône-Alpes, 5/17 farmers (farm prevalence: $29 \%, \mathrm{CI}=11.3-55.9$ ) reported EAA clinical signs in some of their former flocks (4 FC and $1 \mathrm{ALT}$ ). None of the eight farms visited in Pays de la Loire reported EAA clinical signs in former flocks (Table 1).

\section{Age for onset of EAA clinical signs}

Among the 22 farms with current or former EAApositive flocks, 16 farms provided information about age of hens at the start of EAA clinical signs. Abnormal eggs appeared before the production peak (93-95\% of production) in two farms with FC (farm prevalence: $12.5 \%$ ), between 24 and 35 weeks of age in eight farms (farm prevalence: 50\%; 4 ALT and 4 FC), and between 40 and 60 weeks of age in six farms (farm prevalence: $37.5 \%$; 3 ALT and $3 \mathrm{FC}$ ).

\section{Vaccination use as control tool for the EAA syndrome}

Among the farms with at least one former or current experience of EAA, 16 farmers answered about vaccination practice. According to farmers, none of the current EAA-positive flocks were MS-vaccinated. Twelve farmers did not use vaccines to control MS and four EAA-positive farms had used vaccines as a control tool in former positive flocks: autogenous vaccines prepared with an inactivated MS isolate (two farms) and a commercial live vaccine (two farms).

Table 1 Distribution of EAA cases in the 22 affected farms (96 flocks) according to the region and the production system

\begin{tabular}{|c|c|c|c|c|c|c|c|c|c|c|}
\hline \multirow[t]{3}{*}{ Region } & \multicolumn{4}{|c|}{ No. of visited } & \multirow{2}{*}{\multicolumn{3}{|c|}{$\frac{\text { EAA cases in }}{\text { Current flocks }}$}} & & & \\
\hline & \multirow[t]{2}{*}{ Farms } & \multirow[t]{2}{*}{ Flocks } & \multirow{2}{*}{$\begin{array}{l}\text { Flocks in } \\
\mathrm{ALT}^{\mathrm{a}}\end{array}$} & \multirow{2}{*}{$\begin{array}{l}\text { Flocks } \\
\text { in } \mathrm{FC}^{\mathbf{a}}\end{array}$} & & & & \multicolumn{3}{|c|}{ Former flocks } \\
\hline & & & & & $\overline{\mathrm{ALT}^{\mathrm{a}}}$ & $\mathrm{FC}^{\mathrm{a}}$ & Total & $\overline{\mathrm{ALT}} \mathrm{T}^{\mathrm{a}}$ & $\mathrm{FC}^{\mathrm{a}}$ & Total \\
\hline Bretagne & 52 & 69 & 24 & 45 & 0 & 4 & 4 & 3 & 8 & 11 \\
\hline Pays de la Loire & 8 & 9 & 6 & 3 & 0 & 0 & 0 & 0 & 0 & 0 \\
\hline Auvergne-Rhône-Alpes & 17 & 18 & 10 & 8 & $3^{b}$ & 0 & 3 & $1^{b}$ & 4 & 5 \\
\hline TOTAL & 77 & 96 & 40 & 56 & 3 & 4 & 7 & 4 & 12 & 16 \\
\hline
\end{tabular}

${ }^{a} F C$ furnished cages, $A L T$ alternative systems (barn, free-range, organic)

${ }^{\mathrm{b}}$ one farm with one current and one former EAA-positive flock 


\section{Use of laboratory analyses for MS monitoring}

Survey results showed that diagnosis and/or control of mycoplasmosis via laboratory investigation was not a common practice for the farmers surveyed. The monitoring and tracking with serological and/or molecular tests, as suggested by the OIE (2008), was applied in only 11 EAA-positive farms out of the 77 visited farms (14.2\%). In details, three farmers did not provide information about the test used for MS infection detection, two farms were analyzed by PCR methodology (one MSpositive farm), six farms used serology (three MSpositive and one MS-negative farms; results not reported for two farms).

\section{Statistical analysis of the variables studied}

Non dependence between variables studied in this survey on the past 5 years was demonstrated using a multiple correspondence analysis (MCA). For this analysis, in order to get more reliable and interpretable modalities of the date, real values of the date of survey were replaced with the season they belong to. The MCA results are illustrated on Fig. 1. The cumulated percentage of inertia explained with the first two dimensions is equal to $39.1 \%$. The contributions of the categories of variables are given in Fig. 2. It follows that nine categories have a significant contribution to the twodimensional representation: Former.EAA_Yes, MS.Vaccine_Yes, 2016, Auvergne-Rhône-Alpes, Summer, Winter, Syndrome.EAA_Yes, MS.Monitoring_Yes and 2015. More precisely, it is interesting to notice that "MS.Vaccine_Yes" is highly related (probability value ( $p$-value) < $0.001)$ with "Former.EAA_Yes": no EAA problems were detected in current flocks of farms that used MS vaccination after a former EAA-positive flock. One can also notice that "MS.Monitoring_Yes" is highly related ( $p$ value $<0.05$ ) with "Former.EAA_Yes" and "Syndrome.EAA_No": farms detected EAA-positive in the last 5 years and that used laboratory tests for MS monitoring did not show clinical signs of EAA syndrome in the present flocks.

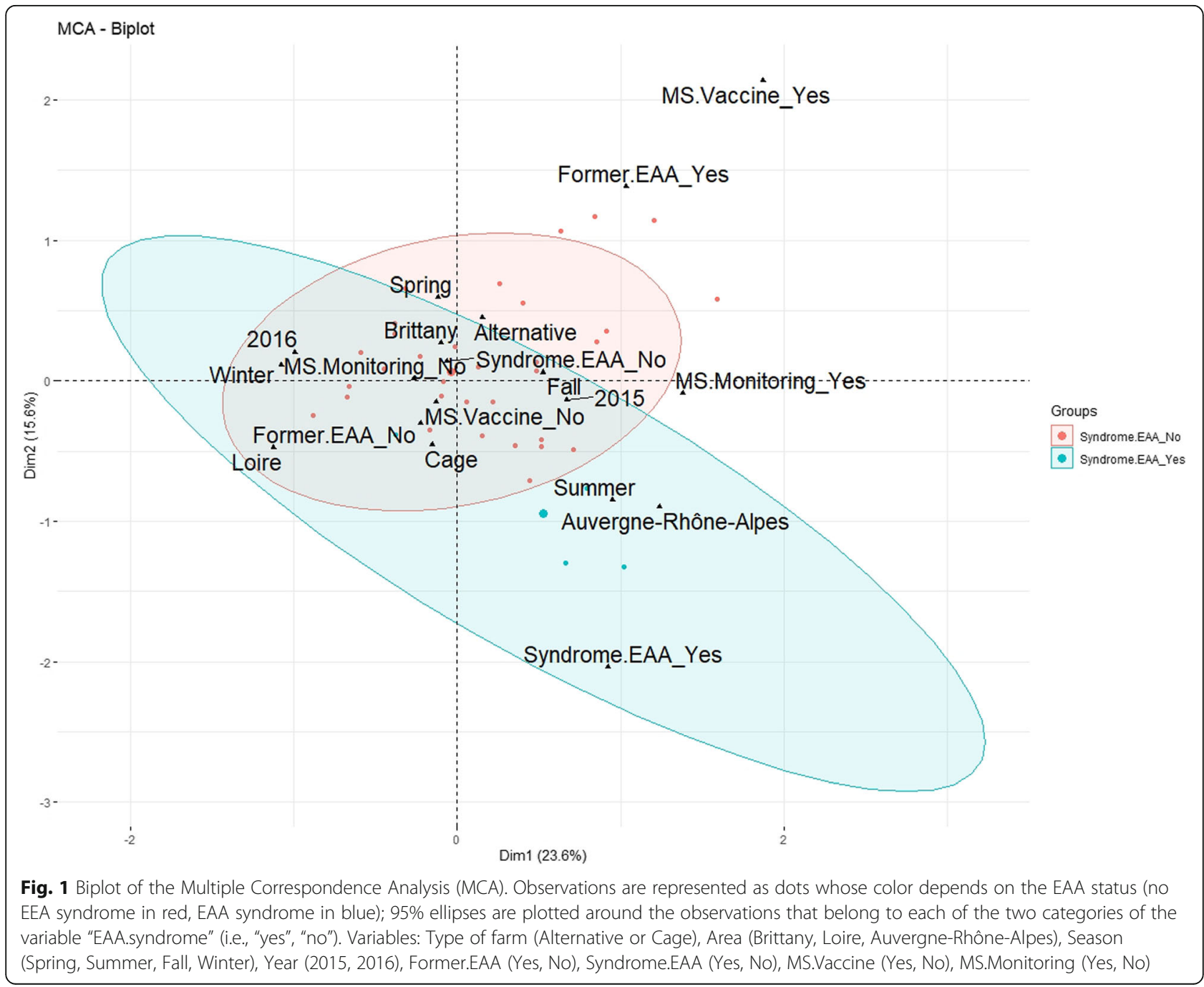




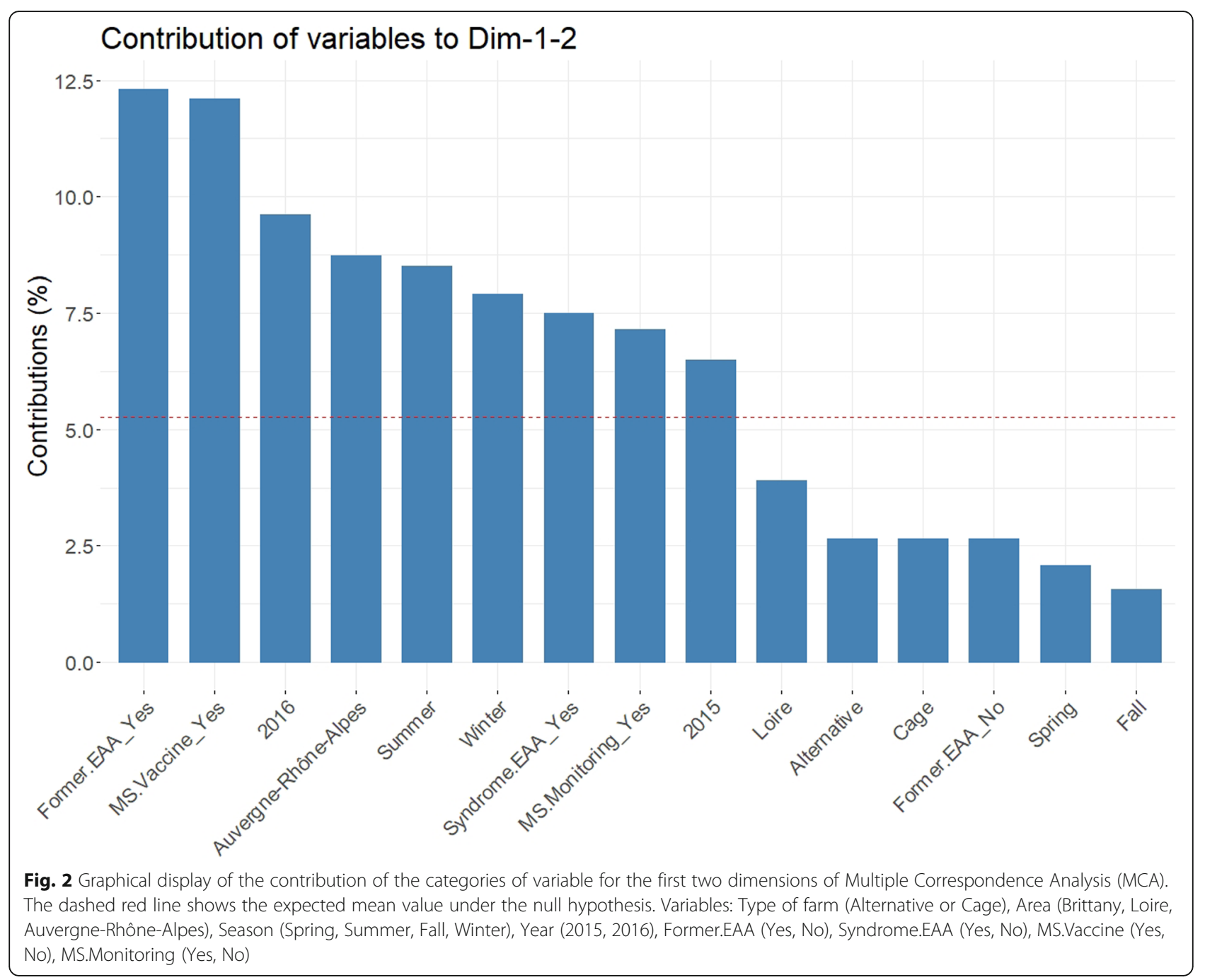

Laboratory results (phase 2): MS detection using PCR

Different types of samples from 28 cases of EAA syndrome clinically detected by veterinarians were sent to our laboratory from January 2015 to June 2017: samples included fresh eggs, tracheal and cloacal swabs, originating from six regions of France (Table 2). M. synoviae was detected by PCR in $25 / 28$ cases $(89.3 \%$ ) (Table 2 ), significantly more frequently from tracheal swabs (321/ 544 positive samples, $59.0 \%)$ than cloacal swabs $(39 / 371$ positive samples, $10.2 \%)$ ( $p$-value $<0.001$ ) (Table 3$)$. For eggs, MS was more frequently detected from albumens (4/111 positive samples, $3.6 \%)$ than egg yolk ( $1 / 110$ positive samples, $0.9 \%)$, but this difference was not statistically significant $(p$-value $=0.68) . M$. synoviae was detected in tracheal swabs of 23/24 (95.8\%) EAApositive cases and in cloacal swabs of 10/14 (71.4\%) EAA-positive cases.

M. synoviae was detected in 5/5 ALT and 20/23 FC farms with EAA in the six different regions where flocks were sampled (Table 2). In ALT farms, MS was detected from $59.3 \%$ of tracheal and $18.8 \%$ of albumen swabs. In FC farms, MS was detected from $59 \%$ of tracheal and $10.5 \%$ of cloacal swabs, and $1.1 \%$ of albumen or egg yolk swabs (Table 3).

\section{M. synoviae isolation by in vitro cultivation}

During this 30 months field study, clones were obtained from different cultures that were found MS-positive by PCR. However, isolation of MS clones was made difficult not only by the presence of bacterial contaminations but also by the presence of another Mycoplasma species in many samples, growing faster than MS in vitro. Assays of cultivation in presence of erythromycin neither prevented the growth of this Mycoplasma species nor allowed better isolation of MS isolates. Analyses performed by Matrix-Assisted Laser Desorption Ionisation - Time-of-Flight mass spectrometry (MALDI-TOF MSP) on 14 clones identified this other species as Mycoplasma pullorum. These results were confirmed based on sequence similarity ( 98.2 to $99.4 \%$ ) of $16 \mathrm{~S}$ rRNA gene 
Table 2 Information on samples collected in layer flocks during phase 2 (2015-2017)

\begin{tabular}{|c|c|c|c|c|c|c|}
\hline Case number & Region $^{\mathbf{a}}$ & Production system $^{\mathbf{b}}$ & Layer age (in weeks) & Sample type (swabs) & Number of samples collected & MS PCR detection ${ }^{c}$ \\
\hline 1 & IF & FC & 52 & trachea/cloaca & $30 / 30$ & $26 / 15$ \\
\hline 2 & ARA & ALT & 62 & albumen/yolk & $15 / 15$ & $3 / 0$ \\
\hline 3 & PACA & $\mathrm{FC}$ & 60 & trachea/cloaca & $30 / 30$ & $13 / 1$ \\
\hline 4 & PACA & $\mathrm{FC}$ & 54 & albumen/yolk & $30 / 30$ & $0 / 0$ \\
\hline 5 & B & $\mathrm{FC}$ & 52 & albumen/yolk & $34 / 34$ & $1 / 0$ \\
\hline 6 & B & $\mathrm{FC}$ & 56 & trachea/cloaca & $12 / 12$ & $9 / 2$ \\
\hline 7 & NA & FC & 56 & trachea/cloaca & $32 / 32$ & $24 / 1$ \\
\hline 8 & B & $\mathrm{FC}$ & 58 & trachea/cloaca & $30 / 30$ & $25 / 2$ \\
\hline 9 & B & $\mathrm{FC}$ & 60 & trachea/cloaca & $30 / 30$ & $20 / 1$ \\
\hline 10 & B & $\mathrm{FC}$ & 65 & trachea/cloaca/albumen/yolk & $30 / 30 / 9 / 9$ & $9 / 1 / 0 / 0$ \\
\hline 11 & ARA & $\mathrm{ALT}$ & 12 & trachea & 10 & 9 \\
\hline 12 & $\mathrm{BFC}$ & $\mathrm{FC}$ & 42 & trachea & 15 & 11 \\
\hline 13 & ARA & $\mathrm{ALT}$ & 40 & trachea/albumen & $20 / 1$ & $18 / 0$ \\
\hline 14 & $\mathrm{BFC}$ & FC & 51 & trachea & 20 & 17 \\
\hline 15 & ARA & FC & 36 & albumen/yolk & $10 / 10$ & $0 / 0$ \\
\hline 16 & ARA & FC & 64 & trachea/cloaca & $30 / 30$ & $20 / 1$ \\
\hline 17 & $\mathrm{BFC}$ & $\mathrm{FC}$ & 62 & trachea/cloaca & $21 / 21$ & $10 / 0$ \\
\hline 18 & B & $\mathrm{FC}$ & 60 & trachea/cloaca & $30 / 30$ & $20 / 7$ \\
\hline 19 & B & $\mathrm{FC}$ & 68 & trachea/cloaca & $30 / 30$ & $0 / 0$ \\
\hline 20 & ARA & $\mathrm{FC}$ & 60 & trachea/cloaca/albumen/yolk & $21 / 21 / 12 / 12$ & $2 / 2 / 0 / 1$ \\
\hline 21 & $\mathrm{BFC}$ & FC & 49 & trachea/cloaca & $20 / 15$ & $15 / 2$ \\
\hline 22 & ARA & $\mathrm{FC}$ & 52 & trachea & 15 & 12 \\
\hline 23 & B & ALT & 61 & trachea & 15 & 4 \\
\hline 24 & B & $\mathrm{ALT}$ & 60 & trachea & 9 & 1 \\
\hline 25 & ARA & FC & 18 & trachea/cloaca & $30 / 30$ & $17 / 4$ \\
\hline 26 & B & $\mathrm{FC}$ & 18 & trachea & 15 & 14 \\
\hline 27 & B & FC & 24 & trachea & 18 & 11 \\
\hline 28 & B & FC & 34 & trachea & 31 & 14 \\
\hline
\end{tabular}

${ }^{a}$ ARA Auvergne-Rhône-Alpes, B Bretagne, BFC Bourgogne-Franche-Comté, IF lle de France, NA Nouvelle Aquitaine, PACA Provence-Alpes-Côte d'Azur

${ }^{b} F C$ furnished cages, $A L T$ alternative systems (barn, free-range, organic)

' Number of MS positive samples (MS PCR performed on initial suspensions and after culture)

Table 3 M. synoviae detection by PCR in tracheal, cloacal, albumen and egg yolk swabs

\begin{tabular}{|c|c|c|c|c|c|}
\hline \multirow[t]{2}{*}{ Samples } & \multicolumn{2}{|l|}{$A L T^{a}$} & \multicolumn{2}{|l|}{$F C^{\mathbf{a}}$} & \multirow[t]{2}{*}{ Total samples } \\
\hline & Farms & Samples & Farms & Samples & \\
\hline Trachea & $4 / 4^{\mathbf{b}}(100 \%)$ & $32 / 54^{c}(59.3 \%)$ & $19 / 20^{\mathbf{b}}(95.0 \%)$ & $289 / 490^{c}(59.0 \%)$ & $321 / 544^{c, d}(59.0 \%)$ \\
\hline Cloaca & NS & NS & 10/14 (71.4\%) & $39 / 371(10.5 \%)$ & $39 / 371^{\mathbf{e}}(10.2 \%)$ \\
\hline Albumen & $1 / 1(100 \%)$ & 3/16 (18.8\%) & $1 / 5(20.0 \%)$ & $1 / 95(1.1 \%)$ & $4 / 111^{\mathbf{f}}(3.6 \%)$ \\
\hline Egg yolk & $1 / 5(0.0 \%)$ & 0/15 (0.0\%) & $1 / 5(20.0 \%)$ & $1 / 95(1.1 \%)$ & $1 / 110^{\mathbf{f}}(0.9 \%)$ \\
\hline Total & 5/5 (100\%) & $35 / 85$ (41.2\%) & $20 / 20(100 \%)$ & 330/1051 (31.4\%) & $365 / 1136(32.1 \%)$ \\
\hline
\end{tabular}

\footnotetext{
aLT alternative systems (barn, free-range, organic), FC furnished cages

${ }^{b}$ number of MS-positive farms/number of sampled farms (percentage of positive farms)

c number of MS-positive samples/total number of samples (percentage of positive samples)

d,e,f results with different letters are statistically different $(P<0.001)$

NS not sampled
} 
of 14 clones with reference sequence of $M$. pullorum (U58504.1). Similarly, alignment of a subset of reads of these 14 clones against local nucleotide database gave a high percentage of similarity with the published complete sequence of $M$. pullorum (CP017813.1). These 14 Whole Genome Shotgun projects have been deposited at DDBJ/ENA/GenBank under the accession numbers PSYD00000000 to PSYQ00000000. The versions described in this paper are versions PSYD01000000 to PSYQ01000000.

Further analyses by MALDI-TOF MSP on cultures showed that $M$. pullorum was present in at least $14 / 25$ flocks (56\%) sampled during this study (Table 4). In total, 38/71 clones were identified as M. pullorum by MALDI-TOF MSP: four cloacal and 24 tracheal clones from FC flocks, one yolk sac and nine tracheal clones from ALT flocks. Additionally 33/71 clones were identified as MS by PCR: three cloacal and 30 tracheal clones from FC flocks.

\section{Discussion}

M. synoviae seroprevalence in layers is high worldwide [10, 11, 16, 23, 28, 31-35]. Surveys performed in France reported a seroprevalence of 60 and $68 \%$ for MS in laying hen flocks in 1999 and 2006, respectively [18, 36]. This high MS prevalence may lead to EAA clinical signs in layers [5]. Since the first observation of the EAA syndrome in 2008 in The Netherlands [5], EAA was detected in different countries including Japan, United Kingdom, Italy, Germany and Korea [5, 12, 13, 26, 37]. In France, the first case of EAA was described in 2009 [14]. However, the prevalence of this syndrome had never been precisely calculated. The present study demonstrated the prevalence of EAA syndrome in the French laying hen flocks (7.3\% prevalence in the studied sample size). These results are in accordance with a previous study conducted with veterinarians, which reported 3 to $12 \%$ prevalence of EAA syndrome in France [38]. The field study also showed that the EAA syndrome is present in different production systems (furnished cages or alternative systems), with a higher presence in ALT farms. These results are in accordance

Table 4 Isolation of Mycoplasma clones from tracheal, cloacal and egg yolk swabs

\begin{tabular}{lllllll}
\hline Samples & $\mathrm{ALT}^{\mathbf{a}}$ & & & $\mathrm{FC}^{\mathbf{a}}$ & & \\
\cline { 2 - 5 } \cline { 5 - 6 } & $\mathrm{MS}^{\mathbf{b}}$ & $\mathrm{MP}^{\mathbf{b}}$ & & $\mathrm{MS}^{\mathbf{b}}$ & $\mathrm{MP}^{\mathbf{b}}$ & Total clones \\
\hline Trachea & 0 & 9 & 30 & 24 & 63 \\
Cloaca & 0 & 0 & 3 & 4 & 7 \\
Egg yolk & 0 & 1 & 0 & 0 & 1 \\
& 0 & 10 & 33 & 28 & 71 \\
\hline
\end{tabular}

${ }^{a} A L T$ alternative systems (barn, free-range, organic), $F C$ furnished cages

${ }^{\mathrm{b}} \mathrm{MS}$ M. synoviae, MP M. pullorum with case reports describing EAA in FC or ALT systems $[5,12,26]$. The production conditions in ALT systems offer a lower bird density per square meter, a good ventilation and the access to open air via outdoor courses. On the other hand, access to an outdoor course increases the risk of exposure to MS infections, because biosecurity measures cannot be as strict as in closed buildings. Presence of MS in backyard chickens [29, 35, $39,40]$, wild birds [8, 41, 42] or in other neighboring farms can therefore be a higher source of infection [10, $15,25]$. Multi-age farms can also increase the risk of infection between flocks in ALT or FC systems [9, 10, 18]. M. synoviae is indeed able to survive in the environment for several days, thus increasing the risk of contamination of flocks by indirect transmission [25, 43, 44].

This work also underlines the possible role of MS vaccination to decrease EAA clinical signs in layer flocks, which is in accordance with previous results showing that MS vaccination could decrease the incidence of EAA-associated lesions and improve flock's performances $[24,25,45,46]$ then remove and reduce EAA clinical signs in layers [24]. However, it cannot be excluded that the significant difference evidenced in this survey between vaccinated and unvaccinated flocks may not be due in part to the introduction of more stringent biosecurity measures after the EAA problems encountered in the previous flock, or to other factors. M. synoviae vaccination was not a common practice at the time of the survey since only $25 \%$ of the EAA-positive farms visited in this study ( $5 \%$ of all the visited farms) used vaccination. This observation is compatible with that reported by Moreira and collaborators in Portugal [10]. Moreover, vaccination with autogenous killed vaccines or MS live vaccine was used only in farms with EAA problems in a former flock.

Laboratory monitoring was another variable studied in this field study and was shown to be statistically linked to the absence of EAA in current flocks. This result might be explained by the fact that farmers that have had a problem of MS infection with development of EAA in a former flock were more sensitive to the MS problem and performed tests to detect the problem earlier, with implementation of treatments (antimicrobial treatments, vaccination, better disinfection between flocks) or stricter biosecurity measures than farmers that did not experience EAA problems before.

One of the limitations of the current study is that the results were based on the farmers' responses instead of laboratory tests. It is possible that there could be other factors than MS infection alone that might be affecting egg quality, such as infectious bronchitis as suggested by Gole et al. [16]. However, the second part of the study showed that in most clinical cases of EAA, laboratory 
analyses demonstrated that MS was present in the flocks.

For the laboratory study, detection of MS DNA and isolation of MS clones were conducted over a 3 year period, from 2015 to 2017: sampling was performed by veterinarians in 28 EAA-positive farms of six regions of France. Although the field survey focused on layers over 59 weeks of age, samples for the laboratory study were collected in flocks at different stages of production: 25 layer flocks in production (22 to 68 weeks of age) and three flocks of future layers in multi-age farms with recurrent problems of EAA (12 to 18 weeks of age).

Results showed that tracheal swabs were the most frequent MS-positive samples by PCR and culture in EAApositive flocks compared to cloacal or egg swabs. This high level of MS detection in tracheal swabs is in accordance with previous studies $[10,12,18,47]$. The difference between tracheal and cloacal swabs may be explained by the fact that MS is known to have a strong tropism for tissues of the respiratory tract [8] and that its cloacal excretion may be too low (under the detection threshold), intermittent or too irregular, as already suggested by Marois et al. [22]. Contaminations by other bacteria and PCR inhibitors may contribute to lower detection results in cloacal samples [22]. However, Ranck et al. [37] showed that cloacal swabs from hens of EAApositive flocks were more frequently detected positive than cloacal swabs from hens of EAA-negative flocks. $M$. synoviae recovery or detection might have been improved by taking samples directly from the reproductive tract of laying hens and not from cloaca, but our study was based on routine collection of samples from live animals following field veterinary practices for final diagnosis. Studies performed on oviductal swabs of hens from EAA-positive flocks at necropsy showed a good MS detection level by PCR (33 to 80\%) but isolation of MS strains was more difficult than from tracheal samples [12, 48]. It should be noted however that isolation of MS from tracheal swabs is not directly related to the development of the syndrome: only a few MS-infected flocks are affected by EAA and appearance of abnormal eggs is associated with the presence of MS at the oviduct level [5, 49].

Results of our study also showed that MS could be detected in most of the farms with EAA clinical signs (25/ 28 sampled flocks, 89.3\%). For two of the three FC farms where MS was not detected, eggs were the only samples sent for laboratory analyses. Since MS detection and isolation from egg samples (albumens or yolk sacs) was significantly lower than from cloacal and tracheal swabs, it might explain the non detection of MS in these flocks. This low percentage of infected eggs found in our study is in accordance with studies on MS vertical transmission showing that only 3 to $10 \%$ of eggs are infected by
MS after a natural or experimental infection of hens [50-53]. However, Catania et al. [12] and Ranck et al. [37] were able to detect MS DNA in 53.3 and $98 \%$ of fresh eggs from EAA-positive flocks, respectively.

In this study, the onset of EAA clinical signs was observed in all stages of production and suggested that the egg lesions observed did not depend on the age of the hen. Very little information about age of EAA onset is available in previous studies: Strugnell and collaborators reported that incidence of abnormal eggs began to increase at around week 42 [26] and Jeon and collaborators reported an EAA outbreak in 54 week-old layers [13]. The hen's age could also affect the egg production and quality [54]; however, in our study, samples were collected from clinical cases representing various age groups.

Isolation of MS clones from cultures of tracheal, cloacal or egg swabs was hampered by the presence of another Mycoplasma species in many samples, growing faster than MS in vitro. Assays performed with FM4 broth medium supplemented with erythromycin failed to arrest the growth of this Mycoplasma species, suggesting its resistance to erythromycin. Analyses performed by MALDI-TOF MSP on 14 clones identified this species as $M$. pullorum. This identification was confirmed by analysis of whole genome sequences obtained on these 14 clones.

Results of in vitro culture with erythromycin are in accordance with results of Whithear et al. [55] showing that 5/5 strains of $M$. pullorum tested were resistant to erythromycin (MIC of $80 \mu \mathrm{g} / \mathrm{mL}$ ), but susceptible to tylosin, suggesting a natural resistance like MS to 14membered ring macrolides [56]. The classification of $M$. pullorum in the Hominis group is another factor that leans toward innate resistance of this species to 14membered ring macrolides like other Mycoplasma species of this group (M. synoviae, M. hyopneumoniae, $M$. hyorhinis and M. bovis for example) [56, 57].

The MALDI-TOF MSP is increasingly used for bacterial identification, but very few studies have been published on its adaptation to different Mycoplasma species [58-61]. In our study, the identification of $14 \mathrm{M}$. pullorum strains by both NGS and MALDI-TOF MSP allowed us to validate the MALDI-TOF MSP technique for routine use within our laboratory on cultures and clones for identification of this Mycoplasma species, because no $M$. pullorum-specific PCR test has been published yet for its rapid detection. This method allowed cheaper, easier and faster identification of $M$. pullorum than biochemical methods or sequencing and should be considered as a reliable method for identification of this species. Further analyses by MALDI-TOF MSP on cultures and clones showed that $M$. pullorum was present in $56 \%$ of samples collected for this study. 
Very few studies have been published on M. pullorum. It was isolated from pheasants and partridges with signs of upper respiratory disease but was considered as a fast-growing saprophytic Mycoplasma species impeding the isolation of another pathogenic Mycoplasma [41]. However, M. pullorum has been isolated alone or with other Mycoplasma species from trachea or air-sac lesions of chickens with respiratory problems $[62,63]$ and from dead chicken embryos [62]. M. pullorum was also identified in dead turkey embryos [64]. Isolation of clones from egg and cloacal swabs in our study and from chicken and turkey embryos in previous published studies strongly suggests the possibility of genital tropism and therefore vertical transmission of M. pullorum. Further studies (experimental infections and/or field surveys, development of a specific PCR to detect this species in samples without a cultivation step) need to be conducted to test whether $M$. pullorum might play a role, as already demonstrated for Infectious Bronchitis virus [5], in the exacerbation of clinical signs of EAA in MS-infected layer farms.

\section{Conclusion}

In conclusion, laboratory results confirmed data showed by the field survey: the EAA syndrome induced by MS is present among different layer production systems (furnished cages and alternative systems) and regions of France with a prevalence of $7.3 \%$ in the studied sample. Subsequent studies are necessary to determine if $M$. pullorum could play a role in the expression of the clinical signs of the EAA syndrome in case of co-infection with M. synoviae.

\section{Methods}

\section{Field survey (phase 1)}

A 12-month field survey was performed between May 2015 and May 2016. Sample size for this survey was calculated considering a population of 46 millions of commercial layers in 2100 farms, with $70 \%$ of laying hens housed in furnished cages (FC) and 30\% in alternative systems (ALT). Three geographical zones concentrating $62 \%$ of commercial layer farms in France were selected: Bretagne, Pays de la Loire and Auvergne-Rhône-Alpes. The two systems of production (ALT and FC) were considered for this study as pathogen contamination pressures may be different between these two systems. This segmentation allowed improvement of the accuracy of the results. The study unit was the flock: a layer population with the same origin and placed in the same house at the same time. The number of flocks to be studied was calculated based on the total number of French laying hen flocks $(n=2100)$ and on an expected prevalence of $9 \%$ [38], at $+/-5 \%$ and with a risk alpha of $5 \%$ [65], thus a total of 126 farms were included in the survey.
The survey presentation to farmers had an introduction about the main clinical signs of EAA syndrome (increased incidence of soft-shelled eggs and egg breakage on harvesting mats and other facilities, with abnormalities confined to the top cone of the egg, up to approximately $2 \mathrm{~cm}$ from the apex, and almost always with a very clear demarcation zone), with pictures of eggs with typical lesions of EAA (cap about $2 \mathrm{~cm}$ around the apex, thinning of the shell at the apex level with cracks and breaks) for better identification of positive cases in current or past flocks. The questionnaires were recorded individually during the investigator's visit with farmers who had layers of more than 59 weeks of age, to ensure that the information collected was after a nearly complete production cycle. The independent variable was the presence or absence of EAA in flocks under study. A flock was classified as EAA-positive if clinical signs characteristic of this syndrome (apex with altered and thinner shell surface and increased translucency) were observed. The dependent variables were: (i) the flock's age at the beginning of EAA syndrome, (ii) the application or not of any vaccine against MS (autogenous or commercial) and (iii) MS monitoring or not throughout the production life of the flock.

\section{Field sample collection for laboratory analysis (phase 2)}

To detect the causative agent of the EAA syndrome, 1136 samples (544 tracheal, 371 cloacal, 111 albumen, and 110 egg yolk swabs) were collected by veterinarians from 28 flocks of different ages in six regions of France (Table 2): 25 layer flocks in production (between 22 and 68 weeks of age) with clinical signs of EAA and three flocks of future layers in farms with recurrent problems of EAA (between 12 and 18 weeks of age) were sampled. These samples were delivered to our laboratory for diagnosis from January 2015 to June 2017. Ethical approval was not required for the study because samples were collected during routine diagnostic examinations by veterinarians with the consent of the farmers (Article 1, 5a of Directive 2010/63/EU).

\section{Isolation of MS by in vitro cultivation}

All swabs were placed in $2 \mathrm{~mL}$ of Frey Medium 4 (FM4) broth [66] supplemented with antimicrobials (Amphotericin B (Sigma-Aldrich) $25 \mu \mathrm{g} / \mathrm{mL}$, Ampicillin (SigmaAldrich) 2 units $/ \mathrm{mL}$ and Colistin (Sigma-Aldrich) $75 \mathrm{mg} /$ $\mathrm{mL}$ ) to obtain initial suspensions. Mycoplasmas were directly cultured by diluting $100 \mu \mathrm{L}$ of initial suspension from each sample in $900 \mu \mathrm{L}$ of FM4 broth supplemented with antimicrobials and serial dilutions up to $10^{-3}$ were performed. All dilutions were incubated at $37+/-2{ }^{\circ} \mathrm{C}$ until the culture developed an acid color change or for a maximum of 30 days. Since MS is naturally resistant to erythromycin [56], cultures were also performed in FM4 
broth medium supplemented with different erythromycin (Sigma-Aldrich) concentrations ranging from 4 to $10 \mu \mathrm{g} / \mathrm{mL}$ when isolation of MS was made difficult due to the presence of other Mycoplasma species. Subcultures onto FM4 agar were performed after the development of an acid color change and agar plates were incubated at $37+/-2{ }^{\circ} \mathrm{C}$ with $5 \% \mathrm{CO}_{2}$ for 5-10 days. Clones were obtained by picking single Mycoplasma colonies under a stereomicroscope and growing them in FM4 broth as described above. Initial suspensions, cultures, and clones were stored at $\leq-65^{\circ} \mathrm{C}$ in $20 \%$ glycerol until further analysis.

\section{M. synoviae DNA detection using polymerase chain reaction $(P C R)$}

Deoxyribonucleic acid (DNA) samples were prepared by cellular lysis according to the method of Kellog and Kwok [67]. Briefly, $1 \mathrm{~mL}$ of initial suspensions, cultures or clones were centrifuged at 12,000 $\mathrm{x} g$ for $15 \mathrm{~min}$ and the pellets were suspended in a mixture of $250 \mu \mathrm{L}$ of solution A (100 $\mathrm{mM} \mathrm{KCl}, 10 \mathrm{mM}$ Tris- $\mathrm{HCl}$ (pH 8.3), $2.5 \mathrm{mM} \mathrm{MgC1}{ }_{2}$ ) and $250 \mu \mathrm{L}$ of solution B (10 mM Tris-HCL (pH 8.3), $2.5 \mathrm{mM}$ $\mathrm{MgCl}_{2}, 1 \%$ Tween 20 and $1 \%$ Nonidet P40). Samples were incubated for $60 \mathrm{~min}$ at $60^{\circ} \mathrm{C}$ prior to proteinase $\mathrm{K}$ heatinactivation at $95{ }^{\circ} \mathrm{C}$ for $15 \mathrm{~min}$, allowed to cool at room temperature and kept at $5+/-3^{\circ} \mathrm{C}$. The presence of MS DNA in samples and cultures was detected by a MSspecific PCR as previously described by Lauerman et al. [68] in a final volume of $50 \mu \mathrm{L}$. Briefly, the PCR mixture contained $200 \mathrm{mM}$ of each primer (MSL1 5'-GAGAAG CAAAATAGTGATATCA-3' and MSL2 5' -CAGTCGTC TCCGAAGTTAACAA-3'), $200 \mu \mathrm{M}$ of each deoxyribonucleotide triphosphate (Eurobio), $5 \mu \mathrm{L}$ of $10 \mathrm{X}$ PCR buffer (Roche), $2 \mathrm{mM}$ of $\mathrm{MgCl}_{2}$ (Bio-Rad), 1.25 unit of Taq polymerase (Roche) and $5 \mu \mathrm{L}$ of DNA samples. A negative control (water, molecular biology grade, Eurobio) and a positive control (MS reference strain WVU 1853) were added to each PCR assay. PCR were performed with a thermal cycler (T100 ${ }^{\text {tw }}$ Bio-Rad): $94{ }^{\circ} \mathrm{C}$ for $5 \mathrm{~min}, 35$ cycles at $94{ }^{\circ} \mathrm{C}$ for $1 \mathrm{~min}, 50^{\circ} \mathrm{C}$ for $1 \mathrm{~min}$, and $72{ }^{\circ} \mathrm{C}$ for $2 \mathrm{~min}$, followed by an elongation step at $72^{\circ} \mathrm{C}$ for $5 \mathrm{~min}$. Amplified DNA products were separated in a $2 \%$ agarose gel in Tris-Borate-ethylenediaminetetraacetic acid (EDTA) (TBE) buffer ( $90 \mathrm{mM}$ Tris, $90 \mathrm{mM}$ borate, $2.5 \mathrm{mM}$ EDTA $\mathrm{pH}$ 8.0) for $1 \mathrm{~h}$ at a constant voltage of $110 \mathrm{~V}$. Amplified products were detected by ultraviolet transillumination with ethidium bromide staining. A GeneRuler 1 kb DNA Ladder (Thermo Fisher Scientific) was used as a molecular size standard: the expected size of MS amplicon was $207 \mathrm{bp}$.

MALDI-TOF mass spectrometry (MALDI-TOF MSP) analysis Clones were thawed, diluted $1 / 10$ and grown in FM4 broth medium in a final volume of $3 \mathrm{~mL}$. Mycoplasma pellets, obtained after centrifugation at 20,000 $\mathrm{x} g$ for 15 min, were washed twice in $1 \mathrm{X}$ phosphate-buffered saline and suspended in $300 \mu \mathrm{L}$ of water and $900 \mu \mathrm{L}$ of absolute ethanol to precipitate proteins. After centrifugation at $20,000 \times g$ for $2 \mathrm{~min}$, the supernatants were removed and the pellets were dissolved in $30 \mu \mathrm{L}$ of $70 \%$ formic acid (Sigma-Aldrich) and $30 \mu \mathrm{L}$ of acetonitrile (Sigma-Aldrich). After centrifugation for 2 min at 20,000 $\mathrm{x} g, 1 \mu \mathrm{L}$ of supernatant was spotted onto a MALDI-TOF MSP 96 target polished steel plate (Bruker Daltonics). After airdrying at room temperature, each sample was overlaid with $1 \mu \mathrm{L}$ of matrix solution: $\alpha$-cyano-4-hydroxycinnamic acid (HCCA, Bruker Daltonics) solubilized in standard solvent (50\% acetonitrile, $47.5 \%$ water and $2.5 \%$ trifluoroacetic acid, Sigma-Aldrich) to obtain a $10 \mathrm{mg} /$ $\mathrm{mL}$ solution. Samples were air-dried at room temperature before MALDI-TOF MSP analysis. Spectra were generated using a Microflex LT Biotyper operating system (Bruker Daltonics). The data was analyzed by the Bruker Biotyper 3.0 software and the Bruker taxonomy library. The degree of spectral concordance was expressed as a logarithmic identification score ranging from 0 to 3 and was interpreted according to the manufacturer's instructions, with a modification of the score that was acceptable for probable species-level identification, which was lowered from $\geq 2.000$ to $\geq 1.700$ [60].

\section{Next-generation sequencing (NGS) of clones}

Several clones giving a $M$. pullorum identification result with MALDI-TOF MSP were sequenced for Mycoplasma species confirmation. DNA was extracted from a $12 \mathrm{~mL}$ culture with the QIAamp DNA Mini Kit (Qiagen) and quantified with a Qubit $^{\circ} 2.0$ fluorometer (Invitrogen). DNA was sheared by sonication using a Bioruptor ${ }^{\ominus}$ Plus (Diagenode) apparatus. Libraries were prepared using NEBNext Ultra DNA library Prep Kit for Illumina and NEBNext Multiplex Oligos for Illumina according to the manufacturer's instructions (New England Biolabs). Size selection and purification steps were conducted with magnetic beads Agencourt AMP pure XP (Beckman-Coulter). Sequencing was performed using Mi-seq Illumina technology (paired-end sequencing $2 \times$ 150 cycles, MiSeq Reagent kit v2-300 Cycles, Illumina). After cleaning with Trimmomatic 0.36 [69] (ILLUMINACLIP:oligos.fasta:2:30:5:1:true LEADING:28 TRAILI NG:28 MAXINFO:40:0.2 MINLEN:36), the 16S rRNA gene and a subset of reads were aligned against local nucleotide database (Megablast 2.2.26).

\section{Statistical analysis}

A Multiple Correspondence Analysis (MCA) [70] was applied to the whole data set to illustrate the underlying relationships between the eight categorical variables under study in a low-dimensional Euclidean space. In 
addition, the observations on which the variables were measured were also plotted and interpreted simultaneously. Observations and categories of the variables were plotted on the same graphical display while using the quasi-barycentric property. The optimal dimension of the Euclidean space to be interpreted was derived from the associated eigenvalues (i.e., transformed into proportion of inertia). Associations between the categories of the variables were uncovered by calculating the chisquare distances [71]. To get more interpretable modalities of the date (i.e., limited number of categories), real values of the date of survey were replaced with the season they belong to. The statistical analysis was performed with the $\mathrm{R}$ software [72] version 3.6.1 using the "FactoMineR" [73] and "factoextra" packages [74]. A significance level ( $p$-value) of $5 \%$ was used.

\section{Abbreviations \\ ALT: Alternative systems; Bp: Base pair; Cl: Confidence interval; ${ }^{\circ} \mathrm{C}$ : Degree Celsius; DDBJ/ENA/GenBank: DNA Databank of Japan / European Nucleotide Archive / GenBank; DNA: Deoxyribonucleic acid; EAA: Eggshell apex abnormality; EDTA: Ethylenediaminetetraacetic acid; ELISA: Enzyme-linked immunosorbent assay; FC: Furnished cages; FM4: Frey medium 4; g: Gravitational acceleration; h: Hour; HCCA: a-cyano-4-hydroxycinnamic acid; kb: Kilobase; M.: Mycoplasma; MALDI-TOF MSP: Matrix-assisted laser desorption ionisation - time of flight mass spectrometry; MCA: Multiple correspondence analysis; min: Minute; $\mu \mathrm{L}:$ Microlitre; $\mathrm{mL}$ : Millilitre; mM: Millimolar; MS: Mycoplasma synoviae; NGS: Next-generation sequencing; OIE: World Organisation for Animal Health; PCR: Polymerase chain reaction; $p$-value: Probability value; RSA: Rapid serum agglutination; TBE: Tris, Borate, EDTA; V: Volt}

\section{Acknowledgements}

The authors thank Loïc Balaine for its help during the field survey, Maelan Cineux and Rachel Busson for cultures and isolation of Mycoplasma strains. Authors would also like to thank veterinarians, technicians and farmers for their precious contribution to this work.

\section{Authors' contributions}

$A G B, I K, V M$ and $M C T$ conceived and designed the project. JC, VM, GC and $C M$ were responsible for organizing the first field study. JC, GC, CM, MCT and AGB participated to the farms' visits (first and/or second field study). MCT, $A G B, C d B$ and MHBA performed the experiments; MCT, SB and PL interpreted the data. MCT and AGB wrote the manuscript. All authors read and approved the final manuscript.

\section{Funding}

These studies were financially supported by the Secretaría de Educación Superior Ciencia y Tecnología del Ecuador (SENASCYT), Programa Becas para Doctorado (PhD) para Docentes de Universidades y Escuelas Politécnicas 2015 (http://www.educacionsuperior.gob.ec) under Grant number 2015AR2Q8444, and the French Ministry for Agriculture and Food under Grant number CASDAR 5447

The funders had no role in study design, data collection and interpretation, or the decision to submit the work for publication.

\section{Availability of data and materials}

The 14 Whole Genome Shotgun projects generated and analysed during the current study have been deposited at DDBJ/ENA/GenBank under the accession numbers PSYD00000000 to PSYQ00000000 (ncbi.nlm.nih.gov). Other datasets used and/or analysed during the current study are available from the corresponding author on reasonable request.

\section{Ethics approval and consent to participate}

This study was carried out in accordance with the recommendations of the Animal-welfare body of ANSES (agreement number C-22-745-1). According to the Directive 2010/63/EU, ethical approval was not required for this study because samples were collected during "non-experimental agricultural practices" (article 1, 5a) by veterinarians with the consent of the farmers.

\section{Consent for publication}

Not applicable.

\section{Competing interests}

The authors declare that they have no competing interests.

\section{Author details}

${ }^{1}$ Mycoplasmology, Bacteriology and Antimicrobial Resistance Unit, Ploufragan-Plouzané-Niort Laboratory, French Agency for Food, Environmental and Occupational Health and Safety (ANSES), Ploufragan, France. ${ }^{2}$ Facultad de Medicina Veterinaria y Zootecnia, Universidad Central del Ecuador, Quito, Ecuador. ${ }^{3}$ Epidemiology and Welfare in Poultry and Rabbits, Ploufragan-Plouzané-Niort Laboratory, ANSES, Ploufragan, France. ${ }^{4}$ Animal Welfare National Coordination, ANSES, Niort, France. ${ }^{5}$ Epidemiology and Welfare in Pigs, Ploufragan-Plouzané-Niort Laboratory, ANSES, Ploufragan, France. ${ }^{6}$ Viral Genetics and Biosafety unit,

Ploufragan-Plouzané-Niort Laboratory, ANSES, Ploufragan, France. ${ }^{7}$ Labocea, Ploufragan, France. ${ }^{8}$ TTAVI, Lyon, France.

Received: 26 July 2019 Accepted: 22 July 2020

Published online: 05 August 2020

References

1. Olson NO, Shelton DC, Bletner JK, Munro DA, Anderson GC. Studies of infectious synovitis in chickens. Am J Vet Res. 1956;17:747-54.

2. Olson NO, Adler HE, DaMassa AJ, Corstvet RE. The effect of intranasal exposure to Mycoplasma synoviae and infectious bronchitis on development of lesions and agglutinins. Avian Dis. 1964;8(4):623-31.

3. Springer WT, Luskus C, Pourciau SS. Infectious bronchitis and mixed infections of Mycoplasma synoviae and Escherichia coli in gnotobiotic chickens. I. Synergistic role in the airsacculitis syndrome. Infect Immun. 1974;10(3):578-89.

4. Kleven SH, King DD, Anderson DP. Airsacculitis in broilers from Mycoplasma synoviae: effect on air-sac lesions of vaccinating with infectious bronchitis and Newcastle virus. Avian Dis. 1972;16(4):915-24.

5. Feberwee A, de Wit JJ, Landman WJ. Induction of eggshell apex abnormalities by mycoplasma synoviae: field and experimental studies. Avian Pathol. 2009:38(1):77-85.

6. Ferguson-Noel N. Introduction: Mycoplasmosis. In: Swayne DE, Glisson JR, LR MD, Nolan LK, Suarez DL, Nair V, editors. Diseases of Poultry. 13th ed. Ames: Wiley; 2013. p. 875-6.

7. Giambrone JJ, Eidson CS, Kleven SH. Effect of infectious bursal disease on the response of chickens to Mycoplasma synoviae, Newcastle disease virus, and infectious bronchitis virus. Am J Vet Res. 1977;38(2):251-3.

8. Stipkovits L, Kempf I. Mycoplasmoses in poultry. Rev Sci Tech. 1996;15(4): 1495-525.

9. Landman WJ, Feberwee A. Field studies on the association between amyloid arthropathy and mycoplasma synoviae infection, and experimental reproduction of the condition in brown layers. Avian Pathol. 2001;30(6):629-39.

10. Moreira FA, Cardoso L, Coelho AC. Epidemiological survey on mycoplasma synoviae infection in Portuguese broiler breeder flocks. Vet Ital. 2015;51(2): 93-8.

11. Buim MR, Mettifogo E, Timenetsky J, Kleven S, Piantino FA. Epidemiological survey on Mycoplasma gallisepticum and M synoviae by multiplex PCR in commercial Poultry. Pesquisas Veterinarias Brasileras. 2009;29:552-6.

12. Catania S, Bilato D, Gobbo F, Granato A, Terregino C, lob L, et al. Treatment of eggshell abnormalities and reduced egg production caused by mycoplasma synoviae infection. Avian Dis. 2010;54(2):961-4.

13. Jeon E-O, Kim J-N, Lee H-R, Koo B-S, Min K-C, Han M-S, et al. Eggshell apex abnormalities associated with mycoplasma synoviae infection in layers. J Vet Sci. 2014;15(4):579-82

14. Gautier-Bouchardon AV, Ferré S, Kempf I. Isolation of Mycoplasma synoviae from two egg-producing layer flocks presenting eggshell apex abnormalities in France. In: IOM, editor. Proceeding of the 18th congress of the International Organization for Mycoplasmology (IOM). Chianciano Terme: IOM; 2010. p. 161 
15. Nascimento ER, Pereira VLA, Nascimento MGF, Barreto ML. Avian mycoplasmosis update. Braz J Poultry Sci. 2005;7(1):1-9.

16. Gole VC, Chousalkar KK, Roberts JR. Prevalence of antibodies to mycoplasma synoviae in laying hens and possible effects on egg shell quality. Prev Vet Med. 2012;106(1):75-8.

17. Kleven SH. Mycoplasma synoviae infection. In: Saif YM, Barnes HJ, Glisson JR, Fadly AM, McDougald LR, Swayne DE, editors. Diseases of poultry. 11th ed. Ames: lowa State Press; 2003. p. 756-66.

18. Dufour-Gesbert F, Dheilly A, Marois C, Kempf I. Epidemiological study on Mycoplasma synoviae infection in layers. Vet Microbiol. 2006;114(12):148-54.

19. McAuliffe L, Ellis RJ, Miles K, Ayling RD, Nicholas RA. Biofilm formation by mycoplasma species and its role in environmental persistence and survival. Microbiology. 2006;152(4):913-22

20. Simmons WL, Bolland JR, Daubenspeck JM, Dybvig K. A stochastic mechanism for biofilm formation by Mycoplasma pulmonis. J Bacteriol. 2007; 189(5):1905-13.

21. Chen H, Yu S, Hu M, Han X, Chen D, Qiu X, Ding C. Identification of biofilm formation by Mycoplasma gallisepticum. Vet Microbiol. 2012;161(1-2):96-103.

22. Marois C, Dufour-Gesbert F, Kempf I. Detection of Mycoplasma synoviae in poultry environment samples by culture and polymerase chain reaction. Vet Microbiol. 2000;73(4):311-8.

23. Landman WJ. Is mycoplasma synoviae outrunning mycoplasma gallisepticum? A viewpoint from the Netherlands. Avian Pathol. 2014; 43(1):2-8.

24. Feberwee A, Morrow CJ, Ghorashi SA, Noormohammadi AH, Landman WJ. Effect of a live mycoplasma synoviae vaccine on the production of eggshell apex abnormalities induced by a M. synoviae infection preceded by an infection with infectious bronchitis virus D1466. Avian Pathol. 2009;38(5): 333-40

25. Kleven SH. Control of avian mycoplasma infections in commercial poultry. Avian Dis. 2008:52(3):367-74

26. Strugnell BW, McMullin P, Wood AM, Nicholas RA, Ayling R, Irvine RM. Unusual eggshell defects in a free-range layer flock in Great Britain. Vet Rec. 2011;169(9):237-8.

27. Mindus C, Puterflam J, Huneau-Salaun A, Cisneros-Tamayo M, GautierBouchardon AV, Chiron G, editors. Field measures implemented to limit the impact of mycoplasma synoviae-induced EAA syndrome in laying hens in France [in French]. Journées de la Recherche Avicole et des Palmipèdes à Foie Gras 2017; Tours, France.

28. Feberwee A, de Vries TS, Landman WJ. Seroprevalence of mycoplasma synoviae in Dutch commercial poultry farms. Avian Pathol. 2008;37(6):629-33.

29. Sun SK, Lin X, Chen F, Wang DA, Lu JP, Qin JP, et al. Epidemiological investigation of mycoplasma Synoviae in native chicken breeds in China. BMC Vet Res. 2017;13(1):115.

30. Agreste. Produits agroalimentaires. In: I'alimentation Mdlaed, editor. GraphAgri France 2016; 2016. p. 19. www.agreste.agriculture.gouv.fr2016.

31. Hagan JC, Ashton NJ, Bradbury JM, Morgan KL. Evaluation of an egg yolk enzyme-linked immunosorbent assay antibody test and its use to assess the prevalence of mycoplasma synoviae in UK laying hens. Avian Pathol. 2004 33(1):93-7.

32. Bailao AM, Parente JA, Pereira M. Soares CMdA. Kinases of two strains of mycoplasma hyopneumoniae and a strain of mycoplasma synoviae: an overview. Genet Mol Biol. 2007;30(SUPPL. 1):219-24.

33. Kapetanov M, Orlic D, Potkonjak D, Velhner M, Stojanov I, Milanov D, et al. Mycoplasma in poultry flocks in the year 2009 compared to the year 2000 and significance of the control measures. Serbia Vet Med Timisoara. 2010; 43(1):249-53.

34. Silva C, Chagas W, Santos R, Gomes L, Ganda M, Lima A. Seroprevalence of Salmonella and mycoplasma in commercial broilers, backyard chickens, and spent hens in the region of Triângulo Mineiro, state of Minas Gerais, Brazil. Revista Brasileira de Ciência Avícola. 2015;17:57-62.

35. Messa Junior A, Taunde P, Zandamela AF, Junior AP, Chilundo A, Costa R, et al. Serological screening suggests extensive presence of mycoplasma gallisepticum and mycoplasma synoviae in backyard chickens in southern Mozambique. J Vet Med. 2017;2017:4.

36. Kermorgant $P$. Les mycoplasmoses aviaires: enquête sérologique réalisée en Bretagne en 1998 [Phd]. Nantes: Université de Nantes; 1999.

37. Ranck MF, Schmidt V, Philipp HC, Voss M, Kacza J, Richter A, et al. Mycoplasma synoviae-associated egg-pole shell defects in laying hens. Berl Munch Tierarztl Wochenschr. 2010;123(3-4):111-8.
38. Gautier-Bouchardon AV. Le syndrome des œufs à extrémité de verre chez la poule pondeuse. Le Nouveau Praticien Vétérinaire. 2012;5(20):40-3.

39. Susuki K, Origila J, Alvarez F, Faccioli M, Silva M, Caballero L, et al. Relative risk estimation for mycoplasma synoviae in backyard chickens in Paraguay. Int J Poult Sci. 2009;8(9):842-7.

40. Xavier J, Pascal D, Crespo E, Schell HL, Trinidad JA, Bueno DJ. Seroprevalence of Salmonella and mycoplasma infection in backyard chickens in the state of Entre Rios in Argentina. Poult Sci. 2011;90(4):746-51.

41. Bradbury JM, Yavari CA, Dare CM. Mycoplasmas and respiratory disease in pheasants and partridges. Avian Pathol. 2001;30(4):391-6.

42. Michiels T, Welby S, Vanrobaeys M, Quinet C, Rouffaer L, Lens L, et al. Prevalence of mycoplasma gallisepticum and mycoplasma synoviae in commercial poultry, racing pigeons and wild birds in Belgium. Avian Pathol. 2016;45(2):244-52

43. Christensen NH, Yavari CA, McBain AJ, Bradbury JM. Investigations into the survival of mycoplasma gallisepticum, mycoplasma synoviae and mycoplasma iowae on materials found in the poultry house environment. Avian Pathol. 1994;23(1):127-43.

44. Marois C, Picault JP, Kobisch M, Kempf I. Experimental evidence of indirect transmission of mycoplasma synoviae. Vet Res. 2005;36(5-6):759-69.

45. Whithear KG. Control of avian mycoplasmoses by vaccination. Rev Sci Tech. 1996;15(4):1527-53.

46. OIE. Terrestrial Manual 2008 Avian mycoplasmosis. 2008. WWW.OIE.INT2008.

47. Feberwee A, Mekkes DR, de Wit JJ, Hartman EG, Pijpers A. Comparison of culture, PCR, and different serologic tests for detection of mycoplasma gallisepticum and mycoplasma synoviae infections. Avian Dis. 2005;49(2): 260-8.

48. Fd S, Brandão M, Silva CD, Machado L, Soares M, Barreto M, et al. Eggshell apex abnormalities in a free-range hen farm with mycoplasma synoviae and infectious bronchitis virus in Rio de Janeiro state, Brazil. Revista Brasileira de Ciência Avícola. 2014;16:101-3.

49. Catania S, Gobbo F, Bilato D, Gagliazzo L, Moronato ML, Terregino C, et al. Two strains of Mycoplasma synoviae from chicken flocks on the same layer farm differ in their ability to produce eggshell apex abnormality. Vet Microbiol. 2016;193:60-6.

50. Carnaghan RB. Egg transmission of infectious synovitis. J Comp Pathol. 1961;71:279-85.

51. Vardaman $\mathrm{TH}$. The resistance and carrier status of meat-type hens exposed to Mycoplasma synoviae. Poult Sci. 1976;55(1):268-73.

52. Vardaman TH, Drott JH. The effect of Mycoplasma synoviae on meat type hens exposed by injection into air sacs, foot pads and trachea and by aerosal. Poult Sci. 1977;56(1):72-8.

53. MacOwan KJ, Atkinson MJ, Bell MA, Brand TF, Randall CJ. Egg transmission of a respiratory isolate of mycoplasma synoviae and infection of the chicken embryo. Avian Pathol. 1984;13(1):51-8.

54. Roberts J. Factors affecting egg internal quality and egg shell quality in laying hens. J Poultry Sci. 2004;41:161-77.

55. Whithear KG, Bowtell DD, Ghiocas E, Hughes KL. Evaluation and use of a micro-broth dilution procedure for testing sensitivity of fermentative avian mycoplasmas to antibiotics. Avian Dis. 1983;27(4):937-49.

56. Aarestrup FM, Kempf I. Mycoplasma. In: Aarestrup FM, editor. Antimicrobial resistance in bacteria of animal origin. Washington DC: ASM Press; 2006. p. 239-48.

57. Gautier-Bouchardon AV. Antimicrobial Resistance in Mycoplasma spp. Microbiol Spectr. 2018:6(3):ARBA-0030-2018.

58. Goto K, Yamamoto M, Asahara M, Tamura T, Matsumura M, Hayashimoto N, et al. Rapid identification of Mycoplasma pulmonis isolated from laboratory mice and rats using matrix-assisted laser desorption ionization time-of-flight mass spectrometry. J Vet Med Sci. 2012;74(8):1083-6.

59. Pailhories H, Rabier V, Eveillard M, Mahaza C, Joly-Guillou ML, Chennebault $J M$, et al. A case report of mycoplasma hominis brain abscess identified by MALDI-TOF mass spectrometry. Int J Infect Dis. 2014;29:166-8.

60. Pereyre S, Tardy F, Renaudin H, Cauvin E, Del Pra Netto Machado L, Tricot A, et al. Identification and subtyping of clinically relevant human and ruminant mycoplasmas by use of matrix-assisted laser desorption ionization-time of flight mass spectrometry. J Clin Microbiol. 2013;51(10):3314-23.

61. Spergser J, Hess C, Loncaric I, Ramírez AS. MALDI-ToF mass spectrometry is a superior diagnostic tool for the identification and differentiation of mycoplasmas isolated from animals. J Clin Microbiol. 2019;57(9):e00316-9.

62. Benčina D, Mrzel I, Tadina T, Dorrer D. Mycoplasma species in chicken flocks with different management systems. Avian Pathol. 1987;16(4):599-608. 
63. Lobo E, García MC, Moscoso H, Martínez S, Kleven SH. Short communication. Strain heterogeneity in Mycoplasma pullorum isolates identified by random amplified polymorphic DNA techniques. Span J Agric Res. 2004:2(4):4.

64. Moalic P-Y, Kempf I, Gesbesrt F, Laigret F. Identification of two pathogenic avian mycoplasmas as strains of mycoplasma pullorum. Int J Syst Evol Microbiol. 1997;47(1):171-4

65. Machin D, Campbell MJ, Tan SB, Tan SH. Sample size tables for clinical studies. Third edition ed. Oxford: Wiley; 2009.

66. Frey ML, Hanson RP, Anderson DP. A medium for the isolation of avian mycoplasmas. Am J Vet Res. 1968;29:2163-71.

67. Kellog DE, Kwok S. Detaction of human inmunodeficency virus. In: Innis MA, Gelfand DH, Sninsky JJ, White TJ, editors. PCR Protocols. San Diego: Academic Press; 1990. p. 337-47.

68. Lauerman LH, Hoerr FJ, Sharpton AR, Shah SM, van Santen VL. Development and application of a polymerase chain reaction assay for mycoplasma synoviae. Avian Dis. 1993;37(3):829-34

69. Bolger AM, Lohse M, Usadel B. Trimmomatic: a flexible trimmer for Illumina sequence data. Bioinformatics. 2014;30(15):2114-20.

70. Greenacre MJ. In: Press A, editor. Theory and applications of correspondence analysis. London: Academic Press; 1984.

71. Agresti A. Inference for Contingency Tables. In: WSiPa, editor. Categorical Data Analysis Statistics. Hoboken: Wiley; 2002.

72. Lê S, Josse J, Husson F. FactoMineR: an R package for multivariate analysis. J Stat Softw. 2008;25(1):1-18.

73. R Core Team. R: a language and environment for statistical computing. $\mathrm{R}$ Foundation for Statistical Computing, Vienna, Austria. 2013. http://www.Rproject.org/.

74. Kassambara A, Mundt F. 2020. https://CRAN.R-project.org/package= factoextra (version 1.0.7). Accessed 7 May 2020.

\section{Publisher's Note}

Springer Nature remains neutral with regard to jurisdictional claims in published maps and institutional affiliations.

Ready to submit your research? Choose BMC and benefit from:

- fast, convenient online submission

- thorough peer review by experienced researchers in your field

- rapid publication on acceptance

- support for research data, including large and complex data types

- gold Open Access which fosters wider collaboration and increased citations

- maximum visibility for your research: over $100 \mathrm{M}$ website views per year

At $\mathrm{BMC}$, research is always in progress.

Learn more biomedcentral.com/submissions 